\title{
Correction to: When behavioural geographic differentiation matters: inter-populational comparison of aggressiveness and group structure in the European perch
}

\author{
Lola Toomey ${ }^{1}$ (D) Martin Bláha ${ }^{2} \cdot$ Emilie Mauduit $^{1} \cdot$ Tatyana Vanina $^{2}$. \\ Margot Baratçabal $^{1}$ - Yannick Ledoré ${ }^{1}$ - Sami Vesala ${ }^{3}$. Pascal Fontaine ${ }^{1}$. \\ Alain Pasquet $^{1,4} \cdot$ Thomas Lecocq $^{1}$
}

Published online: 19 August 2019

(C) Springer Nature Switzerland AG 2019

\section{Correction to: Aquaculture International (2019) 27:4 \\ https://doi.org/10.1007/s10499-019-00343-z}

This article belongs to the special issue European Percid Fish Culture by Żarski et al. and should be included in Volume 27, Issue 4. The link to this special issue can be found here: https://link.springer.com/journal/10499/27/4

Publisher's note Springer Nature remains neutral with regard to jurisdictional claims in published maps and institutional affiliations.

The online version of the original article can be found at https://oi.org/10.1007/s10499-019-00343-z

\section{Lola Toomey}

lola.toomey@univ-lorraine.fr

$\triangle$ Thomas Lecocq

thomas.lecocq@univ-lorraine.fr

1 Université de Lorraine, Inra, URAFPA, F-54000 Nancy, France

2 Faculty of Fisheries and Protection of Waters, South Bohemian Research Centre of Aquaculture and Biodiversity of Hydrocenoses, University of South Bohemia in Ceske Budejovice, Zátiší 728/II, CZ-389 25 Vodňany, Czech Republic

3 Natural Resources Institute Finland, Helsinki, Finland

4 CNRS (Centre national de la Recherche Scientifique), Paris, France 